\title{
REDE DE APOIO À SAÚDE UTILIZADA POR MÃES DE CRIANÇA/ ADOLESCENTE COM PARALISIA CEREBRAL
}

\author{
HEALTH SUPPORT NETWORK USED BY MOTHERS OF CHILDREN/ADOLESCENTS WITH \\ CEREBRAL PALSY
}

\author{
Vera Lucia Freitaga ${ }^{*}$, Viviane Marten Milbrath ${ }^{b^{* *}}$, Sidnei Petroni ${ }^{* * *}$, Susane Flôres \\ Cosentino $^{\mathrm{d}^{* * *}}$, Fernanda Beheregaray Cabral $\mathrm{e}^{* * *}$, Isabel Cristina dos Santos Colomé $\mathrm{e}^{\mathrm{f***}}$ \\ averafreitag@hotmail.com, bvivianemarten@hotmail.com, 'csidneipetroni@yahoo.com.br, \\ ${ }^{d}$ susycosentino@hotmail.com, ${ }^{\mathrm{e}} \mathrm{Cabralfernandab@gmail.com}$, ${ }^{\mathrm{f}} \mathrm{enfbel} @ y$ ahoo.com.br \\ *Universidade Federal do Rio Grande do Sul - Porto Alegre (RS), Brasil \\ **Universidade Federal de Pelotas - Pelotas (RS), Brasil \\ ***Universidade Federal de Santa Maria - Santa Maria (RS), Brasil
}

Data de recebimento do artigo: 24/10/2016

Data de aceite do artigo: 15/02/2017

\section{RESUMO}

Introdução: A mãe/cuidadora de criança/adolescente com paralisia cerebral vive uma sobrecarga no dia a dia. Por esse motivo se faz necessária uma rede de apoio à saúde para que possa cuidar da criança, não dispensando o cuidado de si. Objetivo: Conhecer a rede de apoio à saúde utilizada pelas mães cuidadoras de criança/adolescente com paralisia cerebral para o cuidado de si. Metodologia: Pesquisa exploratória e descritiva com abordagem qualitativa, realizada no período de maio a julho de 2015 , em uma cidade ao norte do Rio Grande do Sul. Participaram do estudo dez máes/cuidadoras. A coleta das informaçôes ocorreu a partir da entrevista semiestruturada e os dados foram analisados seguindo a análise temática de Minayo. Resultados: Os resultados apontaram que a rede de apoio à saúde dessas mães é constituída pelas dimensôes institucional e Unidade Básica de Saúde, focada principalmente na figura do Agente Comunitário de Saúde. Conclusóes: Recomenda-se a ampliaçấo e a consolidação de rede de apoio de natureza multiprofissional para facilitar o acesso à assistência em saúde e a qualidade de vida dessas mães/ cuidadoras.

Palavras-chave: Cuidadores; enfermagem de atenção primária; saúde pública; mães; paralisia cerebral.

\begin{abstract}
Introduction: The mother/caregiver of child/adolescent with cerebral palsy lives an overload on a daily basis. In this sense, there is need for a health support network so they can take care of the child, not dismissing the care of themselves. Objective: To know the health support network used by caregivers/ mothers of children/adolescents with cerebral palsy for the care of themselves. Methodology: Exploratory and descriptive study with a qualitative approach, carried out from May to July 2015 in a city north of Rio Grande do Sul, Brazil. The study included ten mothers/caregivers. Data collection occurred from the semi-structured interviews and were examined according to the thematic analysis of Minayo. Results: The results showed that the health support network of these mothers consists of the institutional and the Basic Health Unit dimensions, focused mainly on the figure of the Community Health Agent. Conclusions: Expansion and consolidation of a multidisciplinary network support are recommended in order to facilitate access to health care and quality of life to these mothers/caregivers.
\end{abstract}

Keywords: Caregivers; primary care nursing; public health; mothers; cerebral palsy. 


\section{Introdução}

A Constituição Federal profere que o Sistema Único de Saúde (SUS) possui três diretrizes: a descentralizaçáo, $o$ atendimento integral e a participaçáo social. Funciona com base em três princípios: universalidade, equidade e integralidade da atenção à saúde. Salienta-se que estes princípios e diretrizes estão em uma rede composta pela população, a estrutura operacional e o modelo de atenção à saúde regionalizada e hierarquizada. $\mathrm{Na}$ rede se incorpora uma necessária horizontalidade e uma diminuição do poder da hierarquia. São pontos que têm algo em comum e singularidade, por isso a importância de colocá-las em contato dentro do território ${ }^{1}$.

"As Redes de Atenção à Saúde (RAS) são definidas como arranjos organizativos de açóes e serviços de saúde, de diferentes densidades tecnológicas, que integradas por meio de sistemas de apoio técnico, logístico e de gestão, buscam garantir a integralidade do cuidado"2.

Segundo a Organização Mundial da Saúde (OMS), as RAS contêm seis modalidades de integração, assim denominadas: um conjunto amplo de intervençóes preventivas e curativas para uma população; os espaços de integração de vários serviços; a atenção à saúde contínua ao longo do tempo; a integraçáo vertical de diferentes níveis de atenção; a vinculação entre a formulação da política de saúde e a gestáo; e o trabalho intersetorial. Com esse conceito, produz-se um conjunto de serviços integrados de saúde como a gestáo e a oferta de serviços de saúde de modo que as pessoas recebam açóes preventivas e curativas contínuas, de acordo com as suas necessidades ao longo do tempo e por meio de diferentes níveis de atenção à saúde 3 .

Nesse contexto, pode-se dizer que a gestão do cuidado no processo de trabalho em redes de atenção à saúde implica numa reorganização das práticas para a promoção da autonomia, com ênfase na centralidade dos usuários, na consolidação das RAS no SUS e na interligação entre si. As Redes de Atenção à Saúde são organizaçóes poliárquicas de conjuntos de serviços de saúde, interligadas entre si por ter uma missão única e com objetivos em comum. Por ser interdependente oferta uma atenção contínua e integral à determinada população adscrita, coordenada pela Atenção Primária à Saúde (APS) prestada no tempo e no lugar certo, com o custo e a qualidade certa e de forma humanizada ${ }^{4}$.

As Estratégias de Saúde da Família (ESF) inseridas nas Unidades Básicas de Saúde (UBS) podem servir como principal ponto de rede em apoio ao cuidado dos indivíduos e seus familiares, uma vez que a ESF é capacitada para conhecer todas as famílias pelas quais é responsável. Conhecendo-as, tem capacidade de identificar os seus principais problemas de saúde, suas situaçóes de risco, suas necessidades assistenciais para um crescimento e desenvolvimento saudável de todos os membros. Estas equipes, portanto, têm responsabilidade em acompanhar as famílias, em especial as que se encontram necessitadas de elevado grau de atençáo 5 .

A ESF inserida na UBS surge como meio de reestruturação da APS, possuindo como sede uma unidade pública de saúde destinada a realizar atenção contínua nas especialidades básicas com uma equipe multiprofissional habilitada para desenvolver as ações de promoção, proteção e recuperação da saúde como ponto de rede de cuidado. As ESF são porta de entrada e interligação com outros pontos da rede, como hospitais, Apaes, laboratórios, etc., resolutiva para $85 \%$ das necessidades dos usuários, e representam um dos princípios básicos, que é a integralidade da atenção (prevenção, promoção, cura, reabilitação, demanda espontânea), além da integração matricial com especialistas, constituindo o local onde existe o maior fluxo de pessoas ${ }^{6}$.

Sendo assim, a ESF consiste em espaço privilegiado para o cuidado de máes/cuidadoras de crianças com paralisia cerebral, tendo em vista a proximidade com as famílias e o trabalho que valoriza e estimula o cuidado de si, por meio da busca da autonomia dos usuários em relação a sua saúde.

Portanto, torna-se importante que a mãe/cuidadora de criança com paralisia cerebral tenha uma rede de apoio à saúde, que a auxilie no cuidado de si, tendo em vista que, muitas vezes, vivenciam uma sobrecarga física e psíquica no seu cotidiano ${ }^{7}$. Estudos têm demonstrado que as mães de crianças/adolescentes com paralisia cerebral direcionam seus filhos como o centro de suas vidas e se dedicam plenamente a eles ${ }^{8}$. Tal dedicação e preocupaçáo com o crescimento e desenvolvimento dos filhos tem levado essas mulheres/mães a colocarem o cuidado com a criança/adolescente em detrimento do cuidado de si, deixando-se em segundo plano?. Essas mães buscam, constantemente, fornecer aos filhos terapêuticas capazes de possibilitar o máximo do desenvolvimento de suas possibilidades existenciais ${ }^{7}$.

O cuidar de si compóe uma complexa e rica série de atitudes ligadas ao fato de ocupar-se e de preocupar-se consigo e é valorizado e percebido como essencial para o ser humano a partir do momento em que este percebe seu direito de viver e a maneira como vive. É certo modo de encarar as adversidades vivenciadas, de estar no mundo, de praticar açóes, de ter relaçóes com o outro, sendo uma maneira de olhar para si mesmo, de praticar açóes de si para consigo, por meio das quais nos assumimos, nos modificamos, nos purificamos, nos transformamos e nos transfiguramos ${ }^{10}$.

O profissional enfermeiro, enquanto coordenador da ESF, poderá elaborar estratégias de cuidado à mulher que possam orientá-la quanto ao cuidado de si e do filho, bem como estabelecer um espaço de troca de 
conhecimentos, planejando o cuidado direcionado a cada uma na sua complexidade.

Exercer o papel de cuidador significa ter zelo, solicitude, desvelo, mesmo não havendo palavras. É uma forma de interação que envolve dedicação, interesse, envolvimento e responsabilidade. Para Waldow ${ }^{11}$, o cuidado pode ser demonstrado através de gestos, posturas, olhares e toques.

Em experiência profissional, na área da saúde, ao trabalhar com crianças/adolescentes com necessidades especiais, notou-se a família nos mais diversos aspectos. Chamava a atenção, dentre essas, a incipiente procura pelas mães às RAS para o cuidado de si. Observou-se empiricamente que o foco do cuidado de enfermagem era quase que exclusivamente na criança/adolescente com necessidades especiais, cabendo a cuidadora uma localização mais à margem dos acontecimentos e, ainda, sendo cobrada em relação aos cuidados com o mesmo. Segundo autores $^{12}$, as cuidadores relataram insatisfação com a sua saúde, sentindo-se sobrecarregadas, manifestando danos a sua saúde física e mental. No entanto, em uma busca em várias bases de dados nacionais e internacionais, não foram encontrados estudos que abordassem o cuidar de si da mãe/cuidadora de crianças com necessidades especiais, sendo este trabalho inédito nesse cenário.

Face ao exposto, percebeu-se a relevância deste estudo, pois os resultados poderão contribuir com o aprendizado, o pensamento crítico e a troca de experiências entre a equipe multiprofissional em saúde, buscando estratégias para a inclusão destas mães na RAS, como apoio, atendendo suas necessidades no que tange o cuidar de si. Para o enfermeiro, em especial, se faz necessário articular as dimensōes política e técnica do fazer para que a gestão do cuidado se constitua nas dimensóes técnica, política, comunicativa e de desenvolvimento da cidadania.

O estudo tem o objetivo de conhecer as redes de apoio à saúde utilizadas pelas mães/cuidadoras de criança/adolescente com paralisia cerebral para o cuidado de si.

\section{Método}

Este estudo tem natureza exploratório-descritivo de abordagem qualitativa ${ }^{13}$. A coleta dos dados foi realizada no período de maio a julho de 2015 , com mães cuidadoras de crianças com paralisia cerebral na Associaçáo de Pais e Amigos dos Excepcionais (Apae), localizada em uma cidade da região norte do Rio Grande do Sul (RS). A Instituição é filantrópica, sem fins lucrativos, de caráter educacional, assistencial, cultural, de saúde, de estudos e pesquisa. Quanto aos recursos humanos, a entidade conta com 36 funcionários, sendo: 22 professores, três auxiliares de serviço, um monitor, dois motoristas, uma secretária, uma psicóloga, duas fonoaudiólogas, uma fisioterapeuta, uma terapeuta ocupacional e uma assistente social.

A Apae apresentou à pesquisadora um total de quinze mães/cuidadoras de criança/adolescente com paralisia cerebral. Dessas, dez se enquadraram nos critérios de inclusão, quais sejam: ser a mãe consanguínea e cuidadora da criança/adolescente com paralisia cerebral com idade entre 5 a 19 anos que frequentem a instituição do estudo; permitir a gravação da entrevista e divulgação dos resultados. As participantes foram identificadas por pseudônimos de M1 a M10, respectivamente, conforme a ordem da entrevista, a fim de manter seu anonimato. As participantes foram selecionadas por carta convite pela pesquisadora em um dos encontros na sala de espera da Apae. Salienta-se que todas as participantes assinaram o Termo de Consentimento Livre e Esclarecido.

As informaçóes foram coletadas por meio de entrevistas semiestruturadas, composta por questionamentos como: Qual ponto da Rede de Atenção à Saúde você utiliza para cuidar de si? (contextualizado o que é a Rede de Atenção à Saúde e mencionados os pontos). Quais açôes você busca na Unidade Básica de Saúde? As entrevistas foram realizadas conforme escolha da participante, no seu domicílio ou na Apae em sala reservada para tal, sendo que quatro entrevistas foram realizadas em domicílio e seis na Apae, as quais foram gravadas e transcritas na íntegra logo após a sua realização.

As informações foram interpretadas segundo a análise temática proposta por Minayo, que consiste em três etapas: pré-análise, exploração dos dados, tratamento dos resultados obtidos e interpretação ${ }^{14}$.

Em atenção às normas da pesquisa envolvendo seres humanos, conforme preconiza a Lei 466/2012 do Ministério da Saúde, o projeto foi aprovado pelo Comitê de Ética em Pesquisa da Faculdade de Medicina da Universidade Federal de Pelotas (CEP/Famed/UFPel) em 26 de março de 2015, sob o número 1.001.573.

\section{Resultados e discussão}

Com a análise das informaçóes emergiram as seguintes categorias: rede de apoio em saúde utilizada pelas mães/cuidadoras de criança/adolescente com paralisia cerebral e agente comunitária de saúde como ponte entre o usuário e a estratégia de saúde da família.

\section{Redes de apoio em saúde utilizadas pelas mães/cuidadoras de criança/adolescente com paralisia cerebral}

As crianças com paralisia cerebral, quando desenvolvem necessidades especiais, demandam cuidados 
especiais, os quais na maioria são ofertados pelas mães ${ }^{7}$. A paralisia cerebral possui vários fatores etiológicos multifatoriais, dividido entre os períodos de ocorrência que são: pré, peri e pós-natal. É também denominada encefalopatia crônica não progressiva da infância, que é consequência de uma lesão estática, a qual afeta o sistema nervoso central em fase de maturação estrutural e funcional ${ }^{15}$.

Ao refletir sobre a complexidade que envolve o cuidar de uma criança com paralisia cerebral, deve-se lançar uma visão mais holística e ao mesmo tempo generalista da saúde para as principais cuidadoras. Entende-se que a atenção dos profissionais de saúde deve ser direcionada tanto à criança/adolescente com paralisia cerebral quanto àquele(a) que cuida diretamente da criança/adolescente. Torna-se fundamental que essa possa dispor de uma RAS para apoio não só para o filho, mas para cuidar de si.

Ao dar voz às mães de crianças/adolescentes com paralisia cerebral sobre qual RAS esta utiliza como apoio para cuidar de si, obtiveram-se as seguintes falas:

Quando preciso de alguma coisa eu venho na Apae [...]. (M3)

Da saúde tenho a Apae, [...] até semana passada fui consultar (referindo-se a UBS) descobri que estava com anemia, até o doutor me deu autorização para fazer meu preventivo, já marquei [...], mas no postão eu sempre fui bem atendida, tanto no hospital também, não tenho o que me queixar, da secretaria de saúde também, quando eu precisava do transporte, de um exame que eu não podia pagar, eles sempre me ajudaram, pelo menos eu sempre dei sorte de conseguir [...]. (M6)

Quanto a saúde eu conto com o hospital e o postinho, vou no plantão qualquer coisa. (M5)

Geralmente vou na Apae, elas são bem legais lá, ou no posto, mas o posto quase não vou [...]. (M10)

Pode-se observar pelos relatos que a Apae, o hospital e o posto de saúde são citados como RAS. A Apae constitui uma entidade filantrópica que, junto à comunidade, se une para prevenir, tratar e promover o bem-estar e o desenvolvimento da pessoa com deficiência, sem levar em consideração a faixa etária ${ }^{16}$. Essa instituição conta com diversos educadores e profissionais de saúde. Pelos relatos pode-se observar que as mães a utilizam como apoio não só para o filho, mas também para o cuidado de si.

Há uma tendência à procura da rede de atenção secundária e terciária, como o hospital e a Apae, fato que pode se configurar pelo vínculo criado pela máe com estas instituiçôes. Pesquisa publicada em 2016 revelou a natureza dos vínculos como determinante na funcionalidade da rede, justificando que, quanto mais fortes são os vínculos, mais forte é a rede ${ }^{17}$.
A rede hospitalar aparece como RAS de apoio às máes, pelo mesmo fato da Apae ser referência, ou seja, pelo vínculo criado em função das demandas do filho. Acredita-se que o vínculo criado, muitas vezes, deve-se ao fato dessas cuidadoras possuírem uma forte ligação com as instituiçóes que prestam atendimento de saúde à criança e por serem os locais que a família mais frequenta em seu cotidiano de cuidados ${ }^{18}$. Assim, a mãe utiliza este ponto de rede também para o cuidado de si.

Pelos relatos pode-se perceber que as mulheres utilizam a ESF, em sua grande maioria, para realizar o exame preventivo para câncer de colo de útero, como se observa nos relatos abaixo:

O posto [...]. Este ano não fiz o preventivo, este ano tenho que fazer, fiz um monte de exame, está tudo bem. (M8)

Se eu precisar, qualquer coisa eu vou ao posto, ou no hospital. [...]. O preventivo eu faço a cada dois anos aqui no posto, tá tudo bem, mas a mamografia nunca fiz. $O$ preventivo eu já tenho marcado lá no posto sabe, a guria lá do posto (Agente Comunitária de Saúde) é bem conhecida minha, ai ela já diz: "tal época tem que fazer de novo". Qualquer duvidazinha que tenho, vou ao posto, ela conversa ou me passa para a enfermeira. (M2)

As mães cuidadoras preocupam-se com a prevenção de agravos à saúde ao se referirem ao exame preventivo de câncer de colo uterino, cuidado importante relacionado à saúde da mulher. No entanto, a M2 aponta uma pessoa de referência (ACS) com quem ela pode dirimir suas dúvidas, demonstrando que o vínculo entre usuários e equipes de saúde é fator determinante na busca pela rede de atenção em saúde.

Outra mãe refere não utilizar os serviços da unidade básica como ponto de rede, como é demonstrado no relato a seguir:

$\mathrm{Na}$ saúde tenho o hospital, a doutora (mencionou o nome) que me acompanhou na gravidez. No posto eu não vou mesmo, quando preciso vou no hospital. [...] Uma vez que tive conjuntivite fui até o hospital, e no dentista vou no sindicato (referindo-se ao Sindicato Rural). (M1)

Neste sentido, torna-se importante discutir sobre o porquê desta máe náo buscar os serviços na UBS, uma vez que esta pode se constituir na porta de entrada do Sistema de Saúde, devendo referenciar o trabalho dos outros níveis de atenção, como hospitais, por exemplo, oferecendo serviços de promoção, proteção e prevenção, como preconiza o SUS. Entretanto, esta família deve estar cadastrada na ESF e sendo acompanhada.

Questôes como essa reiteram a necessidade de criar os sistemas de referência e contrarreferência para que 
o conhecimento da história do cliente não se restrinja apenas a determinada instituição, neste caso, o hospital e o sindicato (Sindicato Rural), mas esteja disponível em todos os níveis de atenção, por meio de estratégias informatizadas 5 .

Outro fato importante é a questão das fichas, visto que a ESF deveria ser livre demanda, conforme mostra o depoimento a seguir:

A médica e o dentista no posto, eles sempre me chamam primeiro sabe, nem precisa tirar ficha quando vou com ele, comigo é diferente, mas se é pra ele, eles atendem na hora, não posso me queixar. (M4)

A M4 menciona que, no posto de saúde, quando é algo para o filho, a chamam primeiro, tanto o médico quanto o odontólogo, e diz: "nem precisa tirar ficha quando vou com ele". Nesse sentido torna-se importante que os profissionais reflitam sobre o respeito aos princípios do SUS no cotidiano do trabalho, especialmente no que se refere à integralidade da assistência, pois a ESF preconiza o atendimento à livre demanda e não a limitação do atendimento por número de fichas distribuídas. É fundamental que seja efetivada a livre demanda e que a questáo apresentada pelo usuário seja acolhida, escutada, problematizada, reconhecida como legítima, visto que o acolhimento a essas situaçóes demandará continuidade no cuidado ${ }^{19}$. Por outro lado, o princípio da equidade vem sendo contemplado porque, quando chega ao serviço, esse usuário tem prioridade de atendimento. A noçâo de equidade diz respeito à necessidade de se "tratar desigualmente os desiguais", de modo a se alcançar a igualdade de oportunidades de sobrevivência, de desenvolvimento pessoal e social entre os membros de uma dada sociedade ${ }^{20}$.

Integralidade é um princípio do SUS, considerado um dos pilares que orienta políticas e açôes de saúde capazes de atender as demandas e necessidades no acesso à rede de serviços considerando as dimensóes biológica, cultural e social de cada usuário. $\mathrm{Na}$ atenção básica, a integralidade constitui-se no cotidiano do trabalho por meio das interaçóes que acontecem entre o usuário e os profissionais ${ }^{21}$.

O SUS assume e consagra os princípios da universalidade, equidade e integralidade da atenção à saúde da população brasileira. Por meio desses princípios é garantido ao cidadão o acesso universal aos bens e serviços que garantam sua saúde e bem-estar, de forma equitativa e integral ${ }^{20}$.

É necessária uma reorientação do modelo assistencial mediado pela ESF. Isso implica a coordenação com níveis de atenção secundário e terciário, principalmente a expansão e fortalecimento da oferta de atenção básica. No seu atual contexto de implantação, a rede de saúde de municípios ainda enfrenta inúmeros obstáculos para oferecer o apoio necessário àqueles que atuam na $\mathrm{ESF}^{22}$.

Outro ponto importante relatado foi em relação à comunicação entre usuários/profissionais:

Eu faço o pré-natal com uma médica cubana, eu quase não entendo ela, porque tem umas palavras que no pais dela significa uma coisa e aqui outra [...]. (M9)

O Programa Mais Médicos foi instituído por meio da Medida Provisória no 621, de julho de 2013, e convertido, posteriormente, na Lei $\mathrm{n}^{\circ} 12.871$, de outubro de 2013, com o objetivo de suprir a falta de profissionais médicos, principalmente nas regiões de maior vulnerabilidade social e sanitária do Brasil. Um dos requisitos do programa é que o médico participante tenha domínio da língua portuguesa e que continue estudando-a, caso contrário, gera reprovação do candidato e inadmissão ao programa. Por outro lado, os pareceres da PGR no $3451 / 2014$ e no 3452/2014 sustentam que o Estatuto do Estrangeiro (Lei 6.815/1980) não exige a proficiência no idioma para a naturalizaçáo, mas apenas que o profissional saiba ler e escrever na língua portuguesa ${ }^{23}$.

Pode-se observar pelo relato da M9 que há dificuldade na comunicação entre a médica pertencente ao programa e os usuários do serviço de saúde. Torna-se fundamental atentar para o diálogo cuidador.

O diálogo cuidador pressupóe capacidade de articular palavras e de recebê-las, requer a conversão contínua de emissor em receptor e de receptor em emissor. O diálogo, no processo de cuidar, é condição necessária para o desenvolvimento na ação de cuidar. Um cuidado onde só um articula palavras e o outro é sujeito passivo, limitando-se a receber determinados vocábulos, configura em má práxis do cuidado ${ }^{24}$.

Entretanto, a efetivação desse diálogo cuidador é um grande desafio, pois não é algo simples, a busca do encontro cuidador mediado pelo diálogo em si é uma arte. É um exercício a ser realizado na prática profissional, contínuo de buscar a palavra adequada a ser utilizada com o outro, o gesto apropriado no momento certo, o respeito em relação ao meu ser como indivíduo histórico e em relação ao outro como um ser autêntico ${ }^{25}$. O diálogo é um exercício a ser realizado no cotidiano de prática dos profissionais de saúde. É necessário que as pessoas se compreendam, pois, caso contrário, não haverá diálogo e a comunicação ficará comprometida, ferindo-se os princípios do SUS. Quando há dificuldade de entendimento dos cuidados dados, pode refletir em falta de entendimento e acolhimento à demanda que levou a usuária ao serviço do seu território.

As mães ora procuram o hospital, ora a UBS. No entanto, ressalta-se que, no município do estudo, durante a noite não há atendimento na UBS e nem na 
Unidade de Pronto Atendimento (UPA). Sendo assim, há necessidade de procurar o plantão hospitalar no caso de urgência e emergência.

\section{Agente Comunitário de Saúde (ACS) como ponte entre o usuário e a equipe da Estratégia de Saúde da Família}

Os dados do estudo mostraram que os ACS são os profissionais que possuem maior contato com as mulheres, mães e cuidadoras.

A Fundação Nacional de Saúde e as Secretarias de Estado de Saúde criaram o Programa de Agentes Comunitários de Saúde (Pacs) no ano de 1991. Em 1994, o Ministério da Saúde criou o Programa de Saúde da Família (PSF) com a intenção de fortalecer o SUS e reorganizar a Atenção Básica de Saúde. A profissão de ACS foi criada pela Lei 10.507 de 10 de julho de 2002 e sancionada pelo entáo presidente da República, Fernando Henrique Cardoso, fixando as diretrizes para o exercício da atividade, estabelecendo também que os ACS sejam responsáveis pelo acompanhamento de 750 pessoas determinadas de acordo com a área de abrangência da Unidade Básica de Saúde ${ }^{26}$.

O papel dos ACS como educadores em saúde é respaldado pela Portaria 1.886/1997 do Ministério da Saúde, permitindo que o ACS realize atividades educativas, desde que o mesmo esteja capacitado pelo(a) profissional enfermeiro(a), visto este(a) ser o(a) supervisor(a). A atuação dos(as) ACS tem demonstrado aspectos positivos na educação em saúde junto à comunidade. $\mathrm{O}$ fortalecimento de vínculo entre unidade e comunidade e a conscientização crítica dos usuários ao se perceberem como protagonistas do processo em saúde são a confirmação de um caminho que possibilita o compromisso com a mudança, no qual todos os sujeitos envolvidos no serviço de saúde compreendem a complexidade da manutenção da saúde. Entretanto, é necessário que se desfaça a assistência curativista e se maximize a prevenção e a qualidade de vida ${ }^{27}$.

O ACS tem sido presença constante na vida dessas mulheres, mães e cuidadoras, como se pode observar nos relatos:

Lá também tem um postinho e tem a Agente de Saúde que vai sempre lá. [...]. Eu faço o preventivo uma vez por ano, só ano passado que não fiz. (M3)

Quando eu não posso pegar um exame eu peço para a Agente de Saúde pegar e eles sempre me levam [...]. Os meus exames eu faço todos os anos. A ACS agenda pra mim, eu vou lá e faço. Fiz mamografia, fiz densitometria óssea. (M4)
A Agente Comunitária de Saúde visita, mas agora está sem, aqui é bem fácil, eu marco hoje, semana que vem vou lá e faço preventivo ou algum exame. (M5)

A ACS torna-se uma educadora em saúde, trabalhando a prevenção e proteção da saúde, uma vez que direciona a mulher à ESF para realização dos exames, especialmente o preventivo do câncer de colo uterino e mamografia, importantes para a prevenção e detecção precoce do câncer. O ACS é um profissional que faz parte da populaçáo, trabalha por ela e para ela. Uma das atividades inerentes e de extrema importância é a de acompanhar as famílias, indivíduos e grupos, com o intuito de estimular a promoção da saúde, prevenção das doenças e seus agravos ${ }^{28}$.

É importante repensar o papel da ESF como ponto de rede e porta de entrada da população para que tenha uma atuação efetiva e com o trabalho de uma equipe multiprofissional. Cabe discutir o papel dos ACS, investindo em sua capacitação e integração à equipe, facilitando o apoio às suas ações.

São esses profissionais que fazem a mediação com a comunidade, cujo trabalho permite a identificação precoce de riscos diversos, como o desenvolvimento de incapacidades, identificação de usuários frágeis com alta dependência e acamados, como é o caso de diversas crianças e adolescentes com paralisia cerebral que necessitam de cuidados diferenciados. Este trabalho poderá ser beneficiado pela utilização de protocolos de aplicação que possam trazer respostas às necessidades e não só identificaçáo de problemas ${ }^{22}$. Os ACS são profissionais importantes na consolidação dos serviços da ESF, por meio de uma ação essencial que é a visita domiciliar, como podemos observar nos relatos a seguir:

A ACS visita regularmente, eles me atendem bem, sabe! (M8)

A ACS vem a cada dois meses lá em casa, agora ela vem mais seguido, acho que é porque eu estou grávida de cinco meses. (M9)

Quem me visita aqui é a Agente de Saúde, que tá sempre junto comigo. (M2)

O ACS conhece a área adstrita e cria vínculo com o usuário fortalecendo a ESF. Assim, a mãe/cuidadora pode sentir-se mais à vontade para expor suas dúvidas, seus anseios e suas preocupaçôes. A ACS se destaca na comunidade pela sua capacidade de se comunicar com as pessoas e, principalmente, pela liderança que exerce atuando como elo cultural unindo o saber científico e o saber popular. 
O vínculo é um relacionamento de confiança, de responsabilidade e de compromisso que se estabelece com a maioria das famílias. Os profissionais buscam satisfazer as necessidades básicas manifestadas pelos indivíduos, favorecendo-lhes a melhoria da qualidade de vida ${ }^{28}$.

No entanto, duas das máes afirmaram que não recebem visita da ACS. Por essas falas pode-se observar que o sistema, muitas vezes, é falho e cabe à enfermeira supervisionar o trabalho das ACS:

Não recebo visita da ACS. Até minha mãe foi no postinho e a Agente disse que tinha falado comigo, mas nunca foi lá em casa, naquele dia eu nem estava em casa. Nunca fiz preventivo, tenho medo até de falar. Quando pensei em fazer eu estava grávida, dai não podia fazer né! (M1)

\section{A Agente Comunitária de Saúde não faz visita. (M6)}

A APS requer recursos humanos e capacitados suficientes para compor a equipe multiprofissional, incluindo na equipe os ACS em número suficiente para atender as famílias adstritas.

Um estudo publicado em 2013 constatou que uma parcela importante dos ACS, cerca de $20,7 \%$, não realiza visita domiciliar ou realiza apenas em parte das famílias cadastradas no território de saúde da família, devido a diversos aspectos como: número de famílias muito elevado; número de horas dispensadas para a atividade insuficiente e por ainda haver uma inadequação do horário destinado às visitas domiciliares ${ }^{29}$.

$\mathrm{O}$ fato de não receber visita do ACS, por vezes, deve-se aos inúmeros desafios que este enfrenta no seu processo de trabalho, como a falta de qualificação, a sobrecarga de trabalho, a baixa remuneração, a dificuldade no desenvolvimento em açôes coletivas e a dificuldade de trabalhar em equipe. Estes fatores limitantes tornam-se geradores de estresse e desmotivação para o trabalho, merecendo atenção especial dos gestores de saúde e do poder público. Portanto, torna-se importante a inserção da educação permanente como estratégia de qualificação da prática profissional dos ACS, pois a incorporação de novos conhecimentos e o desenvolvimento de habilidades técnicas e políticas poderão contribuir para a reorganização do processo de trabalho e o desempenho de suas atividades ${ }^{30}$.

São atribuições do ACS: mapear, realizar e atualizar cadastros familiares, identificar área e indivíduos, orientar as famílias, visitá-las continuadamente, desenvolver açôes educativas de vigilância, dinamizar a comunidade $\mathrm{e}$, principalmente, ser um parceiro que potencializa as adversidades encontradas com mães e filhos com necessidades especiais ${ }^{6}$.

O ACS, como membro da equipe da ESF, no entanto, deve ser capacitado para que possa realizar suas funçôes, pois está em contato permanente com a maioria das entrevistadas, desenvolvendo açóes educativas, visando à promoção da saúde, à prevenção das doenças e ao acompanhamento das pessoas com problemas de saúde, estabelecendo o elo entre a ESF e os usuários.

O ACS busca facilitar o processo do cuidar, uma vez que ele pertence à mesma comunidade que o usuário receptor do cuidado, e que faz a ligação entre usuário e equipe, ponto fundamental para a efetivação do trabalho da Estratégia de Saúde da Família. Afinal, é a partir do que os ACS veem e ouvem dos usuários que as ações de saúde serão organizadas pela equipe.

Eles atuam como mediadores sociais, o que, por um lado, revela o ACS como aquele que traduz para a equipe as necessidades da populaçáo e, por outro, seria a condição para garantia de vinculação e identidade cultural de grupo com as famílias sob sua responsabilidade em relação às ações ofertadas pelo serviço ${ }^{31}$.

\section{Conclusões}

Este estudo contribuiu com o aprendizado, pensamento crítico e troca de experiências entre os/as profissionais de saúde para propor alternativas que possam aproximar as mães/cuidadoras dos serviços públicos de saúde e servir como rede de apoio em saúde na sua integralidade; não só com cuidados primários, mas com o apoio da equipe multiprofissional, visto que, além da criança/adolescente, a mãe também se encontra em situação de vulnerabilidade, muitas vezes, estigmatizada pela sociedade.

Ao refletir sobre o trabalho do profissional nos serviços de saúde, em especial o enfermeiro, e levando em consideração a sua responsabilidade pela organização do serviço, principalmente em nível primário, faz-se necessário conhecimento teórico/prático para a efetividade das açôes. É imprescindível que o profissional atente à definição de perfis e funções, para que todos os atores estejam comprometidos e participem das açóes para a efetividade do trabalho em rede.

Assim, o enfermeiro, enquanto coordenador da Unidade Básica de Saúde, para a efetividade das açóes, deve fazer, em um primeiro momento, um diagnóstico situacional para posteriormente elaborar as estratégias/ planos de ação. A criação de sistemas de regulação e governança é fundamental para o funcionamento da rede, assegurando ao usuário do SUS o conjunto de açóes e serviços de que necessita de forma efetiva, contínua, integral e humanizada.

As mães cuidadoras das crianças/adolescentes com paralisia cerebral tecem sua própria rede de atenção à saúde entre a UBS e atenção secundária e terciária, como Associação dos Pais e Amigos dos Excepcionais e Hospital, mesma rede acessada quando necessita 
cuidados aos filhos, demonstrando que o motivo para o estabelecimento da rede está centrado no vínculo estabelecido com os serviços em momentos anteriores.

Acredita-se que a máe/cuidadora, assim como todos os usuários, têm o direito de escolher suas redes de atenção. No entanto, é fundamental que se permita a realização dessa escolha. A ESF deve servir como um dos pontos fundamentais da rede, configurando-se como porta de entrada do usuário e encaminhamento a outras redes.

Sugere-se para outros estudos investigar o trabalho multiprofissional como ferramenta de consolidação da rede de atenção à saúde às mães/cuidadoras de crianças/ adolescentes com paralisia cerebral, com o objetivo de compreender e mapear pontos consolidados e fragilizados nessa rede, como norte para a integralidade do cuidado em saúde.

\section{Referências}

1. Mendes EV. O cuidado das condiçóes crônicas na atenção primária à saúde: o imperativo da consolidação da estratégia da saúde da família. Brasília, DF: Opas; 2012.

2. Brasil. Portaria no 4.279, de 30 de dezembro de 2010. Estabelece diretrizes para a organização da Rede de Atenção à Saúde no âmbito do Sistema Único de Saúde (SUS). Diário Oficial da Uniâo. Brasília, DF; 31 dez 2010. Seção 1, p. 89.

3. World Health Organization. Integrated health services: what and why? Technical Brief [Internet]. 2008 [citado em 2015 set 10];1. Disponível em: http://bit.ly/2n7t741

4. Mendes EV. Redes de Atenção à Saúde. Ciênc Saúde Coletiva. 2010;15(5):2297-305.

5. Milbrath VM, Amestoy SC, Soares DC, Siqueira HCH. Integralidade e acessibilidade no cuidado à criança portadora de paralisia cerebral. Acta Paul Enferm. 2009;22(6):755-60.

6. Brasil. Portaria $n^{\circ} 2.488$, de 21 de outubro de 2011. Aprova a Política Nacional de Atenção Básica, estabelecendo a revisão de diretrizes e normas para a organizaçáo da Atenção Básica, para a Estratégia Saúde da Família (ESF) e o Programa de Agentes Comunitários de Saúde (PACS). Diário Oficial da União. Brasília, DF; 21 out 2011.

7. Milbrath VM. Criança/adolescente com paralisia cerebral: compreensóes do seu modo de ser no mundo [tese]. Porto Alegre: Universidade Federal do Rio Grande do Sul; 2013.

8. Vieira NGB, Mendes NC, Frota LMC, Frota MA. O cotidiano de mães com crianças portadoras de paralisia cerebral. Rev Bras Promoç Saúde. 2008;21(1):55-60.

9. Fernández-Alcántara M, García-Caro MP, BerrocalCastellano M, Benítez MA, Robles-Vizcaíno C, LaynezRubio C. Experiencias y cambios en los padres de niños con parálisis cerebral infantil: estudio cualitativo. An Sist Sanit Navar. 2013;36(1):9-20.

10. Waldow VR. Cuidar: expressão humanizadora da enfermagem. Rio de Janeiro: Vozes; 2012.

11. Waldow VR. Cuidado colaborativo em instituiçóes de saúde: a enfermeira como integradora. Texto \& Contexto Enferm. 2015;23(4):1145-52.

12. Oliveira MFS, Silva MBM, Frota MA, Pinto JMS, Frota LMCP, Sá FE. Qualidade de vida do cuidador de crianças com paralisia cerebral. Rev Bras Promoç Saúde. 2008;21(4):275-80.

13. Minayo MCS. O desafio do conhecimento: pesquisa qualitativa em saúde. 32a ed. São Paulo: Hucitec; 2013.

14. Minayo MCS. Análise qualitativa: teoria, passos e fidedignidade. Ciênc Saúde Coletiva. 2012;17(3):621-6.

15. Ferrari A, Cioni G. The spastic forms of cerebral palsy: a guide to the assessment of adaptive functions. Itália: Springer; 2010.

16. Souza MX, Dutra LR, Rosa Junior JN, Simóes MRL, Lima AMJ e Dutra IR. Promoçáo do autocuidado aos portadores de necessidades especiais. Interface Comun Saúde Educ. 2014; (Supl 3).

17. Neves ET, Silveira A, Arrué AM, Pieszak GM, Zamberlan KC, Santos RP. Network of care of children with special health care needs. Texto \& Contexto Enferm. 2015;24(2):399-6.

18. Neves ET, Andres B, Silveira A, Arrué AM. A rede social de cuidados de uma criança com necessidade especial de saúde. Rev Eletr Enf. 2013;15(2):533-4.

19. Brasil. Departamento de Atenção Básica. Cadernos de Atenção Básica 28: Acolhimento à demanda espontânea. Brasília, DF: Ministério da Saúde; 2013.

20. Teixeira C. Os princípios do Sistema Único de Saúde. Texto de apoio elaborado para subsidiar o debate nas Conferências Municipal e Estadual de Saúde. Salvador; 2011 [citado em 2015 ago 15]. Disponível em: http://bit.ly/2mOrk8f

21. Silva KL, Sena RR. Integralidade do cuidado na saúde: indicaçóes a partir da formação do enfermeiro. Rev Esc Enferm USP. 2008;42(1):48-56.

22. Motta LBD, Aguiar ACD, Caldas CP. Estratégia Saúde da Família e a atenção ao idoso: experiências em três municípios brasileiros. Cad Saúde Pública. 2015;27(4):779-86.

23. Silva SM, Santos LMP. Estudo das açôes diretas de inconstitucionalidade do Programa Mais Médicos. Cad Ibero Am Direito Sanit. 2015;4(2):67-81.

24. Roselló FT. Antropologia do cuidar. Petrópolis: Vozes; 2009.

25. Milbrath VM, Siqueira HCH, Motta MGC, Amestoy SC. Família da criança com paralisia cerebral: percepção sobre as orientaçóes da equipe de saúde. Texto \& Contexto Enferm. 2012;21(4):921-8.

26. Brasil. Portaria no 648/GM, de 28 de março de 2006. Aprova a Política Nacional de Atenção Básica, estabelecendo a revisão de diretrizes e normas para a organização da Atenção Básica para o Programa Saúde da Família (PSF) e o Programa Agentes Comunitários de Saúde (PACS). Diário Oficial da União. Brasília, DF; 28 mar 2006.

27. Lima MM, Carneiro C, Ramos G, Santos ER, Piva SGN. 
Implantação de salas educativas na estratégia de saúde da família por meio do agente comunitário de saúde como educador em saúde: um relato de experiência. Rev Bras Tecnol Sociais. 2014;1(1):17-24.

28. Carli R, Costa MC, Silva EB, Resta DG, Colomé ICS. Acolhimento e vínculo nas concepçóes e práticas dos agentes comunitários de saúde. Texto \& Contexto Enferm. 2014;23(3):626-32.

29. Costa MS, Araújo FF, Martins LV, Nobre LLR, Araújo FM, Rodrigues CAQ. Agente Comunitário de Saúde: elemento nuclear das ações em saúde. Cienc Saúde Coletiva. 2013;18(7):2147-56.

30. Costa MC, Silva EB, Jahn AC, Resta DG, Colomé ICS, Carli R. Work process of community health agents: possibilities and limits. Rev Gaúcha Enferm. 2012;33(3):134-40.

31. Filgueiras AS, Silva ALA. Agente Comunitário de Saúde: um novo ator no cenário da saúde do Brasil. Physis. 2011;21(3):899-16.

Como citar este artigo:

Freitag VL, Milbrath VM, Petroni S, Cosentino SF, Cabral FB, Colomé ICS. Rede de apoio à saúde utilizada por mães de criança/adolescente com paralisia cerebral. Rev. Aten. Saúde. 2017;15(51):75-83. 